\title{
The Genetic Complexity of Prostate Cancer
}

\author{
Eva Compérat ${ }^{1,2,3, *}$, Gabriel Wasinger $\left.{ }^{3}{ }^{(}\right)$, André Oszwald ${ }^{3}{ }^{(}$, Renate Kain $^{3}{ }^{(1)}$, \\ Geraldine Cancel-Tassin ${ }^{1}\left(\mathbb{D}\right.$ and Olivier Cussenot ${ }^{1,4}$ (D) \\ 1 CeRePP/GRC5 Predictive Onco-Urology, Sorbonne University, 75020 Paris, France; \\ g.cancel@cerepp.org (G.C.-T.); olivier.cussenot@aphp.fr (O.C.) \\ 2 Department of Pathology, Hôpital Tenon, Sorbonne University, 75020 Paris, France \\ 3 Department of Pathology, Medical University of Vienna, 1090 Vienna, Austria; \\ gabriel.wasinger@meduniwien.ac.at (G.W.); andre.oszwald@meduniwien.ac.at (A.O.); \\ renate.kain@meduniwien.ac.at (R.K.) \\ 4 Department of Urology, Hôpital Tenon, Sorbonne University, 75020 Paris, France \\ * Correspondence: eva.comperat@meduniwien.ac.at; Tel.: +33-658246024
}

Received: 28 September 2020; Accepted: 23 November 2020; Published: 25 November 2020

check for updates

\begin{abstract}
Prostate cancer (PCa) is a major concern in public health, with many genetically distinct subsets. Genomic alterations in PCa are extraordinarily complex, and both germline and somatic mutations are of great importance in the development of this tumor. The aim of this review is to provide an overview of genetic changes that can occur in the development of PCa and their role in potential therapeutic approaches. Various pathways and mechanisms proposed to play major roles in PCa are described in detail to provide an overview of current knowledge.
\end{abstract}

Keywords: prostate cancer; germline mutations; somatic mutations; PTEN; TMPRSS2; ERG; androgen receptors

\section{Introduction}

Prostate cancer (PCa) is a major concern in public health, with more than 1.1 million cases worldwide detected every year [1]. Several risk factors for developing PCa are known, e.g., older age, family history and African ethnicity. Despite the refinement of existing treatments and emergence of new management strategies, such as active surveillance and focal therapy, metastatic disease is frequent and mortality is still relatively high, with 26,730 estimated deaths in 2017 [2].

Based on the severity of disease at diagnosis according to differentiation, extension and stage, PCa may be treated in different ways; of particular importance is its initial hormone dependency which allows specific treatments, especially during early-stage disease [1]. Further differences exist between primary, metastatic (mPCa) and castration resistant PCa (CRPCa). Therefore, it is important to know the most important actors, especially the important role of genetics in this hormone-sensitive cancer.

Several studies showed many different genetically distinct subsets of PCa. Various drivers are known, such as androgen-related fusions of ETS-related gene (ERG) and ETS family members, speckle-type pox virus and zinc finger protein (SPOP) mutations, DNA hypermethylation, PIK3/RAS/RAF pathway alterations and DNA damage repair (DDR) pathways.

For better understanding, it is necessary to mention genetic screening, which was explored in the early 2000s and abandoned in 2012 after it was demonstrated that many of the detected PCa were clinically insignificant and did not affect patient life expectancy [3]. In recent years, powerful genetic tests were developed that provide polygenic risk scores for individual patients $[4,5]$. However, a remaining challenge is the recrudescence of clinically relevant $\mathrm{PCa}$, which may also benefit from personalized approaches for risk assessment or therapy. 
Despite recent advances, standard pathology remains a fundamental tool in managing PCa. The Gleason score (GS), reflecting tumor differentiation, is a staple of clinical decision-making, and recent meetings could refine the consensus and diminish interobserver variability [6]. Nevertheless, GS alone will not give all the necessary information; molecular profiling of PCa could provide further information. For instance, a study by Haffner et al. [7] showed that metastasis was not strictly and may result from a tumor region with lower grade, alongside observing PTEN loss. Clinicians need to be increasingly aware that although classical histopathology is a firmly established basis for clinical decisions, it is not the single determinant of PCa behavior.

In recent studies taking a scrutinous approach to Gleason grading of PCa, pathologists showed that cribriform and intraductal PCa, which should be considered Gleason grade 4, were probably more aggressive than the classical Gleason grade 4 pattern. Moreover, several studies underlined a more aggressive behavior of cribriform PCa, partly explained by the underlying molecular aberrations in these tumor patterns. A recent study tested genomic instability by determining the portion of the genome altered and somatic copy number alterations (CNA). Patients with cribriform and/or intraductal PCa and $\geq$ GS 7 had significantly higher percentages of the genome altered than men without this pattern in both cohorts of The Cancer Genome Atlas (TCGA) (2.2 fold; $p=0.0003$ ) and the Canadian Prostate Cancer Genome Network (CPC-GENE) (1.7 fold; $p=0.004$ ) [8]. These patterns were associated with deletions of different chromosomes, such as 8p, 16q, 10q23, 13q22, 17p13 and 1q22, and amplification of 8q24, which plays a major role in PCa evolution and is specifically addressed in this review. CNAs comprised a total of 1299 gene deletions and 369 amplifications in the TCGA dataset. Several of the affected genes were known to be associated with aggressive prostate cancer, such as loss of PTEN, CDH1 and BCAR1 and gain of MYC. Point mutations in TP53, SPOP and FOXA1 were also associated with these PCa patterns but occurred less frequently than CNAs. This study clearly shows that cribriform/intraductal patterns are associated with increased genomic instability, clustering to genetic regions involved in aggressive PCa.

The very complex genomic situation of PCa can be broken down into two major aspects, which need to be considered, namely, the germline genetic background and the somatic changes in PCa (Figure 1).

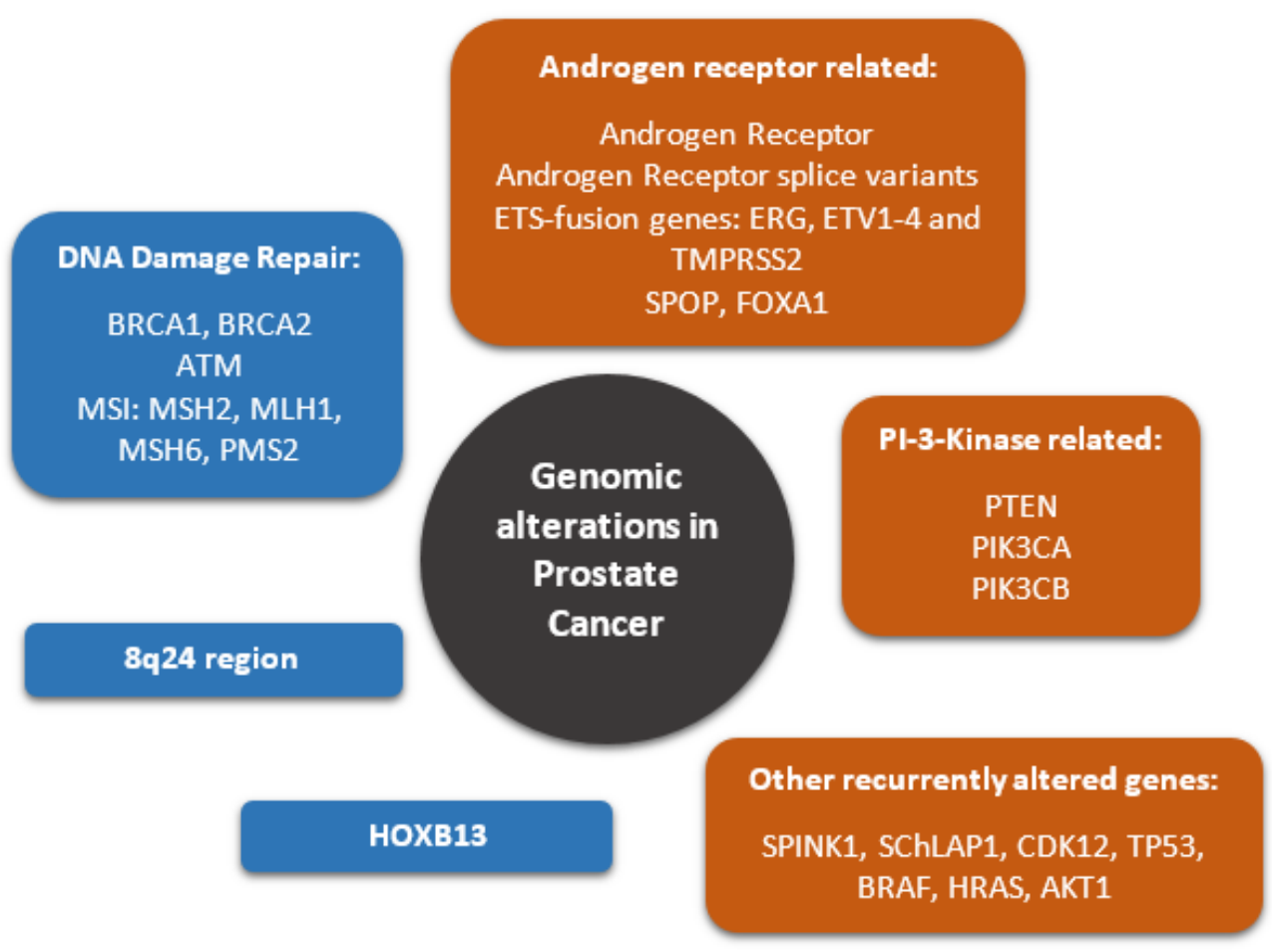

Figure 1. Common genomic alterations in prostate cancer. Germline mutations are highlighted in blue, while typical somatic mutations are highlighted in orange. For abbreviations see full text. 


\section{Germline Mutations Driving PCa}

Hereditary prostate cancer (HPC) is defined by strict clinical criteria and represents $5 \%$ of all newly diagnosed PCa [9]. Inherited predisposition to acquire PCa is genetically determined by the presence of a deleterious mutation of DNA repair genes also related to breast/ovarian cancers (i.e., BRCA1 and BRCA2, ATM, etc.) or PCa-specific risk genes (HOXB13 and 8q24 region) [10]. A recent study performed germline sequencing and analysis of DNA repair genes [11] in 5545 men of European ancestry, including 2775 nonaggressive (localized disease, stage T1/T2 and GS $\geq 6$ tumors) and 2770 aggressive (lethal or metastatic disease, stage T4 or both T3 and GS $\geq 8$ ) PCa cases. The authors found that BRCA2 and PALB2 showed the most statistically significant gene-based disease associations, with $2.5 \%$ of aggressive and $0.8 \%$ of nonaggressive cases carrying deleterious BRCA2 alleles, and $0.65 \%$ of aggressive and $0.11 \%$ of nonaggressive cases carrying deleterious PALB2 alleles. ATM had a nominal association, with $1.6 \%$ of aggressive and $0.8 \%$ of nonaggressive cases carrying ATM alleles. According to typology of genetic risk, predisposition exposes the individual to an earlier age of onset or a more aggressive form of the disease, increasing the risk of death from this cancer. Germline mutations of DNA repair factors are found in only up to $8 \%$ of these patients due to the rarity of the mutations $[12,13]$.

DNA damage response (DDR) pathways are extremely promising targets in PCa treatment. Two prominent factors are breast cancer 1 and 2 genes (BRCA1 and BRCA2). The TCGA research network, testing 333 primary PCas, reported mutations in DNA repair genes in 19\% of primary PCas. Among these, $3 \%$ were affected by BRCA2, including germline as well as somatic truncating mutations. Only one case displayed BRCA1 as a frameshift mutation [14]. If these tumor suppressor genes are mutated heterozygously in the germ line, they can generate aggressive forms, especially mPCa [15]. In a normal setting, BRCA1 and BRCA2 repair double-strand breaks by homologous recombination. In case of a BRCA germline mutation, a somatic loss of function in the wild-type BRCA allele is consequently frequently observed together with defective homologous recombination. Although deleterious BRCA germline variants are rare, these patients were shown to more frequently develop PCa and $\mathrm{mPCa}$, and also exhibit high Gleason scores (grade group 3-5) and worse outcomes [16]. Nevertheless, these tumors did not seem to have specific histological aspects allowing them to be recognized on a standard slide. Interestingly, it was observed that ATM and BRCA1/2 germline mutations were associated with Gleason grade reclassification during active surveillance of carrier patients, with an upgrading of GS from $6(3+3)$ to GS 7(3+4) or 7(4+3) [17].

Another gene implicated in DNA repair mechanisms is ATM, which also plays a role in DNA damage repair and mediates downstream checkpoint signaling. Its prevalence in $\mathrm{mPCa}$ is $1.6 \%$ and therefore it must be considered, especially in these forms of PCa [15]. ATM also integrates the concept of the so-called homologous repair deficiency profile [18]. These mutations were reported in nearly $2.5 \%$ of PCa patients, some detected in lethal PCa (death due to metastatic PCa), with fewer in localized $\mathrm{PCa}$ (low-risk disease, GS $\leq 6$, organ confined) [19]. Interestingly, in Chinese patients, ATM mutations were found in $4.5 \%$ of lethal PCa. In the mentioned American-African-Asian study, no co-mutations BRCA1/2-ATM were detected, indicating that these mutations are probably simultaneously exclusive. This study also demonstrated that mutation carriers displayed higher overall lethality, higher mPCa rates and lower PCa-specific survival in patients with diagnosed $\mathrm{mPCa}$, especially in young patients under 60 years. On the other hand, the lowest carrier rate was among patients who died of $\mathrm{PCa}>75$ years or $>10$ years after their initial PCa diagnosis.

The potential of detecting patients with the above-mentioned germline mutations opens the door to specific treatment approaches, one of the most promising drugs being inhibitors of anti-poly ADP-ribose polymerase (PARP). PARP inhibitors induce cell death because they interfere with a cellular mechanism of single-strand DNA break repair. These occur normally during the cell cycle, but also during oncogenesis. In case of mutation of other abovementioned repair genes, PARP is required to repair both strands, which means that the cell is entirely dependent on PARP for single-strand repair. In context of BRCA mutation and concomitant PARP inhibition, for example, a tumor cell would not be able to perform these measures, resulting in chromosomal instability, cell-cycle arrest and apoptosis [20]. 
A recent study by Hussain et al. [21] showed that patients with PCa harboring at least one mutation in BRCA1, BRCA2 or ATM who received the PARP inhibitor olaparib had significantly longer survival than those who received enzalutamide or abiraterone plus prednisone as control therapy. Other studies also demonstrated that metastatic, castration-resistant PCa (mCRPCa) with BRCA2 germline mutations or deleterious variants showed greater response to platinum-based chemotherapy [22]. This relationship between genotype and responsiveness to platinum chemotherapy was also observed among BRCA2 patients with breast and ovarian cancers. Another study showed concordant results, underlining that biallelic BRCA2 inactivation in mCRPCa could serve as a biomarker for predicting sensitivity to platinum chemotherapy, which showed a clear benefit in biallelic, BRCA-mutated patients [23].

These types of studies underline the necessity of germline testing in special patient groups. Considerations exist regarding who to test for genetic counseling, such as a known mutation in a cancer-susceptibility gene within the family, mPCa, high-risk, localized PCa (grade group 4/5, PSA $\geq 20$, WHO group $\geq 3$ ), young age at PCa detection, family history suggestive of Lynch syndrome and hereditary breast ovarian or prostate cancer. Prostate cancers with deficiency of the DNA mismatch repair (MMR) system are rare, with $1 \%$ at the localized stage and 5\% in the advanced stages [24]. PCa rarely occurs as an unconventional malignancy of the Lynch syndrome spectrum (HNPCC) [25]. These forms of PCa have aggressive anatomopathological criteria, with intraductal forms (25\%), a high incidence of Gleason score 8 and high rates (40-50\%) of metastatic de novo disease which are frequently visceral (30\% of metastatic patients). At the molecular level, they are characterized by a high rate of mutation (tumor mutational burden). Considering their advanced stage, they respond relatively well to androgenic deprivation, but less so to taxanes once castration-resistant. Afflicted patients are a subgroup currently considered candidates and evaluated for anti-PD1 or anti-CTL4 immunotherapy [26,27]. On the germinal level, Pritchard et al. [15] reported that, of 692 patients with mPCa, 12\% showed deleterious germline mutations (1\% involving MSH2, 1\% MSH6 and 2\% PMS2). Abida et al. [26] reported that, of 1346 PCa patients, 3\% showed high microsatellite instability, of which $22 \%$ possessed a germ mutation in a gene associated with Lynch syndrome. Most patients (46\%) had MSH6 mutations.

\section{8q24 Region}

$8 \mathrm{q} 24$ is a hotspot of susceptibility loci for PCa. These risk loci, identified by genome-wide association studies (GWAS), do not affect the coding DNA and are frequently associated with single-nucleotide polymorphisms (SNPs). It was shown that amplification of 8q24 (harboring MYC) is frequent. Often, enhancers such as rs-6983267 interact with MYC and alter sensitivity to certain crucial signaling pathways, e.g., WNT [28,29]. With ongoing research, it is evident that $8 \mathrm{q} 24$ variants play a role in PCa carcinogenesis. A recent meta-analysis determined significant associations between PCa risk and 15 variants in 8q24. The 8q24 region is dense with SNPs; some of these variants might enhance genes implicated in PCa carcinogenesis [29].

Although the inherited component for PCa was previously acknowledged, the identification of genetic variation on 8q24 conferring cancer-specific susceptibility may help to improve screening strategies. Genome-wide studies reported low penetrance of signals influencing the risk. Nevertheless, since risk alleles are relatively common in the population, their cumulative impact is potentially substantial. One recent study underlined several independent signals in different regions and yielded a biological annotation enriched with different elements, such as promoters, enhancers and transcription factor-binding sites, such as AR, ERG and FOXA1 [30]. In another study by the same group, 12 independent risk signals with different variants were described, some of them for the first time (rs1914295, rs190257175 and rs12549761). They were weakly correlated with already known PCa risk markers. On the other hand, this study showed that men with a cumulative risk score had a greater risk of developing PCa than the average population. The described 12 variants accounted for around $25 \%$ of what could be explained as familial genetic risk factor, highlighting the contribution of germline variation on $8 \mathrm{q} 24$. However, although the $8 \mathrm{q} 24$ region is now established as a major region for PCa susceptibility, the underlying biological mechanisms still require further elucidation [10]. 


\section{Somatic Mutations Driving PCa}

Outlier androgen-regulated genes play an important role in PCa development. These genes are generally expressed at low levels, but can show variation in expression of different genomic subsets [31,32]. Especially in light of emerging personalized medicine, it is increasingly important to take into consideration the individual mechanisms driving aggressive PCa.

The gene fusions in PCa are mostly controlled by androgen, fusing to members of the ETS (E26 transformation-specific) family of transcription factors [33]. One of the most cited gene fusions in PCa is the overexpression of TMPRSS2-ERG (T2E) gene fusion. A consequence of this fusion is an overexpression of oncogenic factors; this is frequently present globally, in about $50 \%$ of PCa [33]. TMPRSS2 also fuses to other ETS family genes, such as ETV1, ETV4 and, rarely, ETV5. From a morphological point of view, these tumors frequently display particular aspects, such as macronuclei, signet cell rings, cribriform aspects and intraductal carcinoma. The prognostic impact of T2E is still a matter of controversy. T2E acts as an aberrant transcription factor with oncogenic properties. Several papers indicated that its presence was an indicator of aggressive phenotype and poor prognosis [34-36]. Some authors claimed that it was the most important prognostic factor in patients treated with prostatectomy [37]. Furthermore, it was proposed to be a risk marker for lymph-node metastasis and poorly differentiated disease, as well as biochemical recurrence at five years $[37,38]$. Nevertheless, the data are still controversial, and T2E is not taken into consideration for decision-making at the moment. Several contrasting studies found no clinical significance of the TMPRSS2-ERG fusion [38-40]. Interestingly, recent studies showed that T2E-positive and -negative PCa are two different molecular groups of $\mathrm{PCa}$, suggesting that the T2E status determines the nature of metastasis-related gene signatures $[40,41]$. In T2E-positive cases overexpression in mPCa was seen for several genes (GMNN, TROAP and WEE1). In T2E-negative cases, completely different metastasis-associated genes were expressed, such as ASPN, BGN and TYMS. Therefore, the authors concluded that, according to the T2E status, different genes are linked to the development of mPCa. In patients with overexpression of ASPN, BGN and TYMS, shorter event-free survivals were exhibited. TYMS (thymidylate synthetase), for instance, plays a role in DNA replication and repair. Interestingly, neither PTEN nor TP53 mutations biased the results. Finally, the study showed that the T2E status is not a strong prognostic biomarker per se, but determines the prognostic value of other biomarkers [41].

Another interesting outlier gene is SPINK1, which seems to be, in most cases, mutually exclusive with ERG overexpression [41]. SPINK1, located on 5q32, encodes a protein which functions as a trypsin inhibitor. SPINK1 positivity was shown to be an independent predictor of shorter biochemical recurrence and progression-free survival. Recombinant SPINK1 protein is able to stimulate cell proliferation in benign prostate tissue. A recent study showed that SPINK1 overexpression is linked to higher PTEN expression and lower AR (androgen receptor) expression, with the authors further suggesting that SPINK1 protein expression may not be a predictor of recurrence or lethal PCa amongst men treated by radical prostatectomy. SPINK1 and ERG proteins were not entirely mutually exclusive in this study, as some previous studies suggested [42].

Another important outlier to mention is SChLAP1, a noncoding RNA gene, located on 2q31. Apparently, SChLAP1 has no coding potential, is located in the nucleus and is associated with ETS gene fusion as well as with mPCa. SChLAP1 seems to coordinate cell proliferation and metastatic spread. High expression is associated with lethal PCa, independently of tumor differentiation (Gleason score), tumor stage, PTEN status and age. In a multivariate analysis, SChLAP1 predicted mPCa within 10 years (odds ratio $=2.45$ ) [43].

Obviously, single gene outliers alone are limited in their results and application. These genes might become the basis of patient risk stratification and adaptations in treatment, e.g., more intense earlier treatment or targeted therapies, and will probably become more available in the upcoming years to facilitate genetic and individual subclassification [44]. 


\section{Recurrently Altered Genes}

PCa has a lower mutational burden than many other epithelial tumors. The recent TCGA paper showed several significantly mutated genes, such as SPOP, TP53, FOXA1, PTEN and others [14]. Clinically relevant genes, such as BRAF, HRAS and AKT1, as well as the $\beta$-catenin pathway and the DNA repair pathway (see above), also showed importance.

Loss of PTEN (located on 10q23) is frequently observed and is closely related to MYC overexpression. The latter is found on 8q24. Both together seem to play a role in high-risk PCa.

PTEN loss is associated with adverse findings in early PCa and occurs in approximatively $15 \%$ as homozygous deletions. PTEN loss or mRNA-based genomic signatures can be useful to help determine whether definitive therapy is required, and its loss seems to be more frequent in patients with African ancestry [45]. Early investigations already showed that loss of PTEN, even when detected by immunohistochemistry, was a predictor of aggressive metastatic disease. A paper by Haffner et al. [7] demonstrated that PTEN mutation was not present in morphological, higher grade lesions surrounding a tumor with PTEN loss when the Gleason score was lower. Associated TP53 and SPOP mutations were reported in the same patient. Interestingly, lymph node metastasis did not harbor the same mutations, suggesting an independent clonal/subclonal origin of these lesions. Genetically, there is strong evidence to suggest that poorly differentiated PCa (Gleason score 9/10) has a higher level of genomic instability with an increased rate of copy-number alterations and alterations in key signaling pathways (TP53, PTEN and RB1) associated with resistance to androgen deprivation therapy (ADT) [14]. The function of PTEN is closely linked to the PIK3 pathway, in which PTEN is generally considered a negative regulator. PIK3CA was shown to be frequently mutated, either via activation of mutational hotspots, coincidently activating mutations or amplification. According to the literature, PTEN-deleted tumors are likely to be PIK3CB-dependent; a coexistent loss and mutation of PTEN and PIK3CB might increase PIK3 pathway output and indicate PCa with AR signaling inhibition. PIK3 pathway and DNA repair alterations seem to be more frequent in metastatic specimens [14].

MYC overexpression is an early event in prostate cancer development. Apparently, concomitant with PTEN loss via characterized HOXB13 transcription control, genomic instability and aggressive disease with a high risk of metastases are initiated. These tumors typically show a high Gleason score and disease progression. On the other hand, isolated MYC activation and PTEN were reported to be insufficient to induce invasive $\mathrm{PCa}$, with cells remaining in a precancerous stage (high-grade prostate intraepithelial neoplasia (PIN)) [46]. A recent study from Liu et al. [47] showed that gain of MYC and loss of PTEN resulted in elevated PCa mortality associated even with single copy-number changes. Regarding the interplay of these two factors, MYC overexpression can induce genetic instability, while PTEN might repress this process in PCa cells. Recent results suggested that PTEN might play a role in DNA repair, and if PTEN is lost, high levels of DNA damage that normally repress apoptosis due to increased PIK3 signaling are introduced [48].

One of the genes recurrently mutated in PCa is SPOP, an E3 ubiquitin ligase adaptor protein of the ubiquitin-proteasome system. Mutations may affect the degradation of developmental regulators of PCa, including AR. SPOP plays a role in several further important cellular functions, and intervenes in transcription, cell-cycle regulation and apoptosis.

SPOP mutations were previously described in precancerous lesions and primary tumors of the prostate, suggesting that SPOP mutations are early and recurrent events in the development of PCa [7]. SPOP mutations were identified in 6-13\% of primary prostate adenocarcinomas and $14.5 \%$ of metastatic prostate cancers, but data regarding expression in distant metastasis are sparse [49]. Recent studies showed that SPOP mutations are less frequent in metastatic than in primary tumors ( $8 \%$ versus $11 \%$ ) [14]. In the abovementioned article by Haffner et al. [7] describing the clonal evolution of a PCa in metastasis, SPOP was shown to be mutated in the lethal metastatic cell clone. In this context, it is intriguing that SPOP is also a component of the DNA damage response (DDR).

One PCa-relevant direct substrate of SPOP is the androgen receptor (AR) [50], which harbors a SPOP-binding motif. When binding to SPOP, AR undergoes ubiquitin-mediated degradation. AR splice 
variants that lack the SPOP-binding motif escape this degradation. Interestingly, PCa-associated SPOP mutants do not bind to AR or promote its degradation. SPOP-mediated degradation of AR is driven by antiandrogens and blocked by androgens. It is not clear whether SPOP can interact with other nuclear receptors [51].

It is unclear whether the same SPOP mutations are present in different ethnicities, since some authors described differences according to the patients' ancestry. We [52] and others observed different mutation frequencies between African and European patients, with SPOP mutations differing significantly between both groups. In our study, SPOP mutations were found in more than $20 \%$ of patients with African origin compared to $10 \%$ of European origin. In contrast, a recent study analyzing 720 PCa samples from six international cohorts, including Caucasian, African-American and Asian PCa patients, showed that SPOP mutations were variably frequent (4.6-14.4\%), but found no association with ethnicity. Hence, the authors concluded that SPOP mutations were not associated with ethnicity, biochemical recurrence, clinical parameters or pathological parameters [53]. In light of inconsistent data, more studies are needed to make a conclusive statement.

CDK12 is a gene also implicated in DNA repair by regulation of the expression levels of different DNA repair damage response genes. CDK12 is recurrently mutated in aggressive localized PCa [52] and in mPCa [54]. CDK12 biallelic loss is associated with focal tandem duplications. Moreover, CDK12 mutations are related to increased gene fusion, which can yield neoantigens and induce strong immune infiltration, suggesting that patients with these mutations could benefit from immune checkpoint immunotherapy [54].

\section{Androgen Receptors}

PCa is a hormone-sensitive cancer, and androgen receptors (AR) play a major role in the treatment and development of PCa. For advanced PCa, ADT is the standard of care, but is decisively ineffective in castration-resistant PCa (CRPCa) [1]. Under ADT treatment, circulating testosterone indicates the androgen suppression level. In CRPCa, the activity of AR remains elevated, despite reduced androgen levels. In recent years, second-generation, AR-targeting therapies were developed in order to treat CRPCa with agents to antagonize AR and to suppress extragonadal androgen (coming from the adrenal gland, for instance) [55].

The AR gene, located on Xq11-12, is a major transcriptional regulator in the normal prostate, but also in PCa cells. The AR, a steroid hormone receptor, forms a complex with heat-shock protein 90 (HSP-90). When binding with androgen, it undergoes a change, allowing nuclear translocation, DNA binding and regulation of gene transcription [56]. Different structural variants exist, and some AR were previously implicated in aggressive tumor activity (see below). The AR gene may undergo genomic alterations such as point mutations, which can induce structural changes. These alterations, specifically seen in CRPCa, can help to understand the dependence of CRPCa on androgen-independent AR signaling.

After ligand binding, the AR is translocated into the nucleolus, forms a dimer and binds to the androgen-response element of the promoter or enhancer of target genes [57]. Furthermore, the AR dimer forms a complex with coactivator- and coregulatory proteins in different regions and regulates gene expression with diverse functions. These are located downstream of the androgen response element, including fusion genes (TMPRESS2-ERG), transcription factors (FOXP1, NKX3.1) and others. Many coactivators interacting with different AR domains are implicated in AR activation in therapy-resistant PCa. While normal AR activity on transcription is ligand-driven, AR transcript variants can encode truncated AR proteins lacking a ligand-binding domain, which can activate AR-target genes in the absence of androgens [58].

The spectrum of genes regulated by AR deserves special attention. AR has transcriptional activity and structural variants exist which play roles in the outcome of the patient. However, it is unknown to what extent individual primary PCa tumors differ in androgen sensitivity or dependence. Androgen activity is a central axis in PCa evolution, and drives most ETS fusion genes [26]. ETS fusion 
genes are under AR control, but the ETS fusion-positive groups have different AR transcriptional activity. More frequent events, such as androgen-regulated fusions of ERG or ETS family members, form distinct PCa groups (T2E, see above). The most frequent drivers are ERG, ETV1-4, SPOP and FOXA1 mutations [14]. TMPRSS2 is the most frequent fusion partner of all ETS fusions and is androgen-related. Tumors with SPOP or FOXA1 mutations have the highest AR transcriptional activity, as SPOP mutations deregulate AR and AR co-activators [59]. In PCa. two different changes affect the AR pathway. The output is controlled by AR mRNA and protein expression, but also by the expression and mutations of AR cofactors [60]. FOXA1, which can be mutated, is a transcription factor that targets AR and plays an obvious role in PCa oncogenesis. A subset of these mutations also harbor SPOP mutations and consequently produce high AR levels.

It must be mentioned that the AR is the most frequently aberrant gene in $\mathrm{MCRPCa}$, with around $63 \%$ aberrant expression [12]. Point mutations are found in 15-30\% of CRPCa, most of the mutations residing in the ligand-binding domain. These point mutations can activate AR with a specific point mutation (T878A), which also activates resistance to second generation AR agonists [61]. These mutations were detected in 13\% of CRPCa patients with abiraterone resistance. A second observed mechanism was the amplification of the AR receptor, seen in up to 50\% of patients with CRPCa [62]. In case of ADT, low androgen levels still exist. In case of AR amplifications, PCa cells can survive under ADT, leading to progression of CRPCa. Change in androgen biosynthesis also plays a role. For instance, during ADT, the adrenal gland still produces androgens, while CRPCa overexpresses converting enzymes, converting weak androstenedione levels into DHT to activate AR [63].

The AR splice variants (AR-Vs) have different mRNA sequences than the full-length AR (AR-FL). Around 22 AR-Vs are currently known, most of them lacking the ligand-binding domain (LBD), which is the target of existing AR therapy. Most of these AR-Vs mediate active AR signaling, which means that they can act without the presence of androgens or AR-FL [64]. One of the best-described variants is AR-V7, which also lacks the LBD. AR-V7, known to be an important factor in the treatment of CRPCa, can already be detected in primary tumors and surrounding normal prostate tissue. This is surprising, since truncated AR splice variants were proposed to be expressed predominantly in mCRPCa, and their presence was associated with hormone-therapy resistance, at least for AR-V7. However, the TCGA study showed that these splice variants are already expressed in therapy-naive primary PCa [14]. Structural alterations of AR-Vs may occur in the same allele, leading to a generation of AR-Vs displaying deletions and duplications within the AR LBD. AR-V expression can be regulated by both splicing enhancer sequences and also protein kinase pathways [65].

It could be beneficial to obtain AR-V7 data before treating patients with MCRPCa, as a recent study suggested [66]. The authors showed that patients with mCRPCa exhibiting nuclear localized AR-V7 in circulating tumor cells had better outcomes when treated by taxanes than by AR signaling inhibitors. In a follow-up study, Graf et al. [67] showed that AR-V7-positive patients who were treated with taxanes exhibited better survival, while those who were AR-V7-negative exhibited better survival when treated with AR signaling inhibitors. Therefore, in the era of emerging personalized medicine, the status of the most important splice variants could become an important clinical criterion in the future.

\section{Conclusions}

As this short overview shows, genomic changes in PCa development are extremely complex and many different factors need to be considered. One major challenge of advanced disease is that many proposed underlying mechanisms are still insufficiently understood or unclear due to contrasting results, and thus cannot yet be leveraged as refined therapeutic approaches. However, science is progressing rapidly. This review provides a snapshot of the current knowledge, but in the upcoming years, more data will be available to treat this frequent cancer more effectively.

Author Contributions: Conceptualization, E.C. and O.C.; methodology, E.C., O.C. and G.C.-T.; software, G.W., A.O.; validation, E.C., O.C. and G.C.-T.; formal analysis, G.W., A.O., R.K.; investigation, E.C.; writing-original draft 
preparation, E.C., O.C., G.W., A.O.; writing—review and editing, R.K.; visualization, G.W.; supervision, E.C. and O.C.; project administration, R.K.; All authors have read and agreed to the published version of the manuscript.

Funding: This research received no external funding.

Conflicts of Interest: The authors declare no conflict of interest.

\section{References}

1. Lam, T.B.L.; MacLennan, S.; Willemse, P.-P.M.; Mason, M.D.; Plass, K.; Shepherd, R.; Baanders, R.; Bangma, C.H.; Bjartell, A.; Bossi, A.; et al. EAU-EANM-ESTRO-ESUR-SIOG Prostate Cancer Guideline Panel Consensus Statements for Deferred Treatment with Curative Intent for Localised Prostate Cancer from an International Collaborative Study (DETECTIVE Study). Eur. Urol. 2019, 76, 790-813. [CrossRef] [PubMed]

2. Siegel, R.L.; Miller, K.D.; Jemal, A. Cancer Statistics, 2017. CA Cancer J. Clin. 2017, 67, 7-30. [CrossRef] [PubMed]

3. Giri, V.N.; Knudsen, K.E.; Kelly, W.K.; Abida, W.; Andriole, G.L.; Bangma, C.H.; Bekelman, J.E.; Benson, M.C.; Blanco, A.; Burnett, A.; et al. Role of Genetic Testing for Inherited Prostate Cancer Risk: Philadelphia Prostate Cancer Consensus Conference 2017. J. Clin. Oncol. 2018, 36, 414-424. [CrossRef] [PubMed]

4. Huynh-Le, M.-P.; Fan, C.C.; Karunamuni, R.; Walsh, E.I.; Turner, E.L.; Lane, J.A.; Martin, R.M.; Neal, D.E.; Donovan, J.L.; Hamdy, F.C.; et al. A Genetic Risk Score to Personalize Prostate Cancer Screening, Applied to Population Data. Cancer Epidemiol. Biomark. Prev. 2020, 29, 1731-1738. [CrossRef] [PubMed]

5. Viste, E.; Vinje, C.A.; Lid, T.G.; Skeie, S.; Evjen-Olsen, Ø.; Nordström, T.; Thorsen, O.; Gilje, B.; Janssen, E.A.M.; Kjosavik, S.R. Effects of replacing PSA with Stockholm 3 for diagnosis of clinically significant prostate cancer in a healthcare system-the Stavanger experience. Scand. J. Prim. Health Care 2020, 38, 315-322. [CrossRef]

6. Epstein, J.I.; Egevad, L.; Amin, M.B.; Delahunt, B.; Srigley, J.R.; Humphrey, P.A. Grading Committee The 2014 International Society of Urological Pathology (ISUP) Consensus Conference on Gleason Grading of Prostatic Carcinoma: Definition of Grading Patterns and Proposal for a New Grading System. Am. J. Surg. Pathol. 2016, 40, 244-252.

7. Haffner, M.C.; Mosbruger, T.; Esopi, D.M.; Fedor, H.; Heaphy, C.M.; Walker, D.A.; Adejola, N.; Gürel, M.; Hicks, J.; Meeker, A.K.; et al. Tracking the clonal origin of lethal prostate cancer. J. Clin. Investig. 2013, 123, 4918-4922. [CrossRef]

8. Böttcher, R.; Kweldam, C.F.; Livingstone, J.; Lalonde, E.; Yamaguchi, T.N.; Huang, V.; Yousif, F.; Fraser, M.; Bristow, R.G.; van der Kwast, T.; et al. Cribriform and intraductal prostate cancer are associated with increased genomic instability and distinct genomic alterations. BMC Cancer 2018, 18, 8. [CrossRef]

9. Cancel-Tassin, G.; Cussenot, O. Genetic susceptibility to prostate cancer. BJU Int. 2005, 96, 1380-1385. [CrossRef]

10. Matejcic, M.; Saunders, E.J.; Dadaev, T.; Brook, M.N.; Wang, K.; Sheng, X.; Olama, A.A.A.; Schumacher, F.R.; Ingles, S.A.; Govindasami, K.; et al. Germline variation at 8q24 and prostate cancer risk in men of European ancestry. Nat. Commun. 2018, 9, 4616. [CrossRef]

11. Darst, B.F.; Dadaev, T.; Saunders, E.; Sheng, X.; Wan, P.; Pooler, L.; Xia, L.Y.; Chanock, S.; Berndt, S.I.; Gapstur, S.M.; et al. Germline sequencing DNA repair genes in 5545 men with aggressive and non-aggressive prostate cancer. J. Natl. Cancer Inst. 2020. [CrossRef] [PubMed]

12. Robinson, D.; Van Allen, E.M.; Wu, Y.-M.; Schultz, N.; Lonigro, R.J.; Mosquera, J.-M.; Montgomery, B.; Taplin, M.-E.; Pritchard, C.C.; Attard, G.; et al. Integrative Clinical Genomics of Advanced Prostate Cancer. Cell 2015, 162, 454. [CrossRef] [PubMed]

13. Daly, M.B.; Pilarski, R.; Berry, M.; Buys, S.S.; Farmer, M.; Friedman, S.; Garber, J.E.; Kauff, N.D.; Khan, S.; Klein, C.; et al. NCCN Guidelines Insights: Genetic/Familial High-Risk Assessment: Breast and Ovarian, Version 2.2017. J. Natl. Compr. Cancer Netw. 2017, 15, 9-20. [CrossRef] [PubMed]

14. Cancer Genome Atlas Research Network The Molecular Taxonomy of Primary Prostate Cancer. Cell 2015, 163, 1011-1025. [CrossRef]

15. Pritchard, C.C.; Mateo, J.; Walsh, M.F.; De Sarkar, N.; Abida, W.; Beltran, H.; Garofalo, A.; Gulati, R.; Carreira, S.; Eeles, R.; et al. Inherited DNA-Repair Gene Mutations in Men with Metastatic Prostate Cancer. N. Engl. J. Med. 2016, 375, 443-453. [CrossRef] 
16. Mitra, A.; Fisher, C.; Foster, C.S.; Jameson, C.; Barbachanno, Y.; Bartlett, J.; Bancroft, E.; Doherty, R.; Kote-Jarai, Z.; Peock, S.; et al. Prostate cancer in male BRCA1 and BRCA2 mutation carriers has a more aggressive phenotype. Br. J. Cancer 2008, 98, 502-507. [CrossRef]

17. Carter, H.B.; Helfand, B.; Mamawala, M.; Wu, Y.; Landis, P.; Yu, H.; Wiley, K.; Na, R.; Shi, Z.; Petkewicz, J.; et al. Germline Mutations in ATM and BRCA1/2 Are Associated with Grade Reclassification in Men on Active Surveillance for Prostate Cancer. Eur. Urol. 2019, 75, 743-749. [CrossRef]

18. Pennington, K.P.; Walsh, T.; Harrell, M.I.; Lee, M.K.; Pennil, C.C.; Rendi, M.H.; Thornton, A.; Norquist, B.M.; Casadei, S.; Nord, A.S.; et al. Germline and somatic mutations in homologous recombination genes predict platinum response and survival in ovarian, fallopian tube, and peritoneal carcinomas. Clin. Cancer Res. 2014, 20, 764-775. [CrossRef]

19. Na, R.; Zheng, S.L.; Han, M.; Yu, H.; Jiang, D.; Shah, S.; Ewing, C.M.; Zhang, L.; Novakovic, K.; Petkewicz, J.; et al. Germline Mutations in ATM and BRCA1/2 Distinguish Risk for Lethal and Indolent Prostate Cancer and are Associated with Early Age at Death. Eur. Urol. 2017, 71, 740-747. [CrossRef]

20. Ashworth, A.; Lord, C.J. Synthetic lethal therapies for cancer: What's next after PARP inhibitors? Nat. Rev. Clin. Oncol. 2018, 15, 564-576. [CrossRef]

21. Hussain, M.; Mateo, J.; Fizazi, K.; Saad, F.; Shore, N.; Sandhu, S.; Chi, K.N.; Sartor, O.; Agarwal, N.; Olmos, D.; et al. Survival with Olaparib in Metastatic Castration-Resistant Prostate Cancer. N. Engl. J. Med. 2020. [CrossRef] [PubMed]

22. Pomerantz, M.M.; Spisák, S.; Jia, L.; Cronin, A.M.; Csabai, I.; Ledet, E.; Sartor, A.O.; Rainville, I.; O'Connor, E.P.; Herbert, Z.T.; et al. The association between germline BRCA2 variants and sensitivity to platinum-based chemotherapy among men with metastatic prostate cancer. Cancer 2017, 123, 3532-3539. [CrossRef] [PubMed]

23. Lord, C.J.; Ashworth, A. The DNA damage response and cancer therapy. Nature 2012, 481, 287-294. [CrossRef] [PubMed]

24. Sharma, M.; Yang, Z.; Miyamoto, H. Loss of DNA mismatch repair proteins in prostate cancer. Medicine (Baltimore) 2020, 99, e20124. [CrossRef] [PubMed]

25. Beebe-Dimmer, J.L.; Kapron, A.L.; Fraser, A.M.; Smith, K.R.; Cooney, K.A. Risk of Prostate Cancer Associated With Familial and Hereditary Cancer Syndromes. J. Clin. Oncol. 2020, 38, 1807-1813. [CrossRef]

26. Abida, W.; Cheng, M.L.; Armenia, J.; Middha, S.; Autio, K.A.; Vargas, H.A.; Rathkopf, D.; Morris, M.J.; Danila, D.C.; Slovin, S.F.; et al. Analysis of the Prevalence of Microsatellite Instability in Prostate Cancer and Response to Immune Checkpoint Blockade. JAMA Oncol. 2019, 5, 471-478. [CrossRef]

27. Graham, L.S.; Montgomery, B.; Cheng, H.H.; Yu, E.Y.; Nelson, P.S.; Pritchard, C.; Erickson, S.; Alva, A.; Schweizer, M.T. Mismatch repair deficiency in metastatic prostate cancer: Response to PD-1 blockade and standard therapies. PLoS ONE 2020, 15, e0233260. [CrossRef]

28. Tuupanen, S.; Turunen, M.; Lehtonen, R.; Hallikas, O.; Vanharanta, S.; Kivioja, T.; Björklund, M.; Wei, G.; Yan, J.; Niittymäki, I.; et al. The common colorectal cancer predisposition SNP rs6983267 at chromosome 8q24 confers potential to enhanced Wnt signaling. Nat. Genet. 2009, 41, 885-890. [CrossRef]

29. Tong, Y.; Yu, T.; Li, S.; Zhao, F.; Ying, J.; Qu, Y.; Mu, D. Cumulative Evidence for Relationships Between 8q24 Variants and Prostate Cancer. Front. Physiol. 2018, 9, 915. [CrossRef]

30. Dadaev, T.; Saunders, E.J.; Newcombe, P.J.; Anokian, E.; Leongamornlert, D.A.; Brook, M.N.; Cieza-Borrella, C.; Mijuskovic, M.; Wakerell, S.; Olama, A.A.A.; et al. Fine-mapping of prostate cancer susceptibility loci in a large meta-analysis identifies candidate causal variants. Nat. Commun. 2018, 9, 2256. [CrossRef]

31. Hellwig, B.; Hengstler, J.G.; Schmidt, M.; Gehrmann, M.C.; Schormann, W.; Rahnenführer, J. Comparison of scores for bimodality of gene expression distributions and genome-wide evaluation of the prognostic relevance of high-scoring genes. BMC Bioinform. 2010, 11, 276. [CrossRef] [PubMed]

32. Kamoun, A.; Cancel-Tassin, G.; Fromont, G.; Elarouci, N.; Armenoult, L.; Ayadi, M.; Irani, J.; Leroy, X.; Villers, A.; Fournier, G.; et al. Comprehensive molecular classification of localized prostate adenocarcinoma reveals a tumour subtype predictive of non-aggressive disease. Ann. Oncol. 2018, 29, 1814-1821. [CrossRef] [PubMed]

33. Kumar-Sinha, C.; Tomlins, S.A.; Chinnaiyan, A.M. Recurrent gene fusions in prostate cancer. Nat. Rev. Cancer 2008, 8, 497-511. [CrossRef] [PubMed]

34. Hemminki, K.; Ji, J.; Försti, A.; Sundquist, J.; Lenner, P. Concordance of survival in family members with prostate cancer. J. Clin. Oncol. 2008, 26, 1705-1709. [CrossRef] [PubMed] 
35. Brandt, A.; Sundquist, J.; Hemminki, K. Risk for incident and fatal prostate cancer in men with a family history of any incident and fatal cancer. Ann. Oncol. 2012, 23, 251-256. [CrossRef]

36. Jansson, K.F.; Akre, O.; Garmo, H.; Bill-Axelson, A.; Adolfsson, J.; Stattin, P.; Bratt, O. Concordance of tumor differentiation among brothers with prostate cancer. Eur. Urol. 2012, 62, 656-661. [CrossRef]

37. Nam, R.K.; Sugar, L.; Yang, W.; Srivastava, S.; Klotz, L.H.; Yang, L.-Y.; Stanimirovic, A.; Encioiu, E.; Neill, M.; Loblaw, D.A.; et al. Expression of the TMPRSS2:ERG fusion gene predicts cancer recurrence after surgery for localised prostate cancer. Br. J. Cancer 2007, 97, 1690-1695. [CrossRef]

38. Attard, G.; Clark, J.; Ambroisine, L.; Fisher, G.; Kovacs, G.; Flohr, P.; Berney, D.; Foster, C.S.; Fletcher, A.; Gerald, W.L.; et al. Duplication of the fusion of TMPRSS2 to ERG sequences identifies fatal human prostate cancer. Oncogene 2008, 27, 253-263. [CrossRef]

39. Yoshimoto, M.; Joshua, A.M.; Chilton-Macneill, S.; Bayani, J.; Selvarajah, S.; Evans, A.J.; Zielenska, M.; Squire, J.A. Three-color FISH analysis of TMPRSS2/ERG fusions in prostate cancer indicates that genomic microdeletion of chromosome 21 is associated with rearrangement. Neoplasia 2006, 8, 465-469. [CrossRef]

40. Saramäki, O.R.; Harjula, A.E.; Martikainen, P.M.; Vessella, R.L.; Tammela, T.L.J.; Visakorpi, T. TMPRSS2:ERG fusion identifies a subgroup of prostate cancers with a favorable prognosis. Clin. Cancer Res. 2008, 14, 3395-3400. [CrossRef]

41. Gerke, J.S.; Orth, M.F.; Tolkach, Y.; Romero-Pérez, L.; Wehweck, F.S.; Stein, S.; Musa, J.; Knott, M.M.L.; Hölting, T.L.B.; Li, J.; et al. Integrative clinical transcriptome analysis reveals TMPRSS2-ERG dependency of prognostic biomarkers in prostate adenocarcinoma. Int. J. Cancer 2020, 146, 2036-2046. [CrossRef]

42. Flavin, R.; Pettersson, A.; Hendrickson, W.K.; Fiorentino, M.; Finn, S.; Kunz, L.; Judson, G.L.; Lis, R.; Bailey, D.; Fiore, C.; et al. SPINK1 protein expression and prostate cancer progression. Clin. Cancer Res. 2014, 20, 4904-4911. [CrossRef] [PubMed]

43. Prensner, J.R.; Zhao, S.; Erho, N.; Schipper, M.; Iyer, M.K.; Dhanasekaran, S.M.; Magi-Galluzzi, C.; Mehra, R.; Sahu, A.; Siddiqui, J.; et al. RNA biomarkers associated with metastatic progression in prostate cancer: A multi-institutional high-throughput analysis of SChLAP1. Lancet Oncol. 2014, 15, 1469-1480. [CrossRef]

44. Kim, H.; Skowronski, J.; Den, R.B. Prognostic outlier genes for enhanced prostate cancer treatment. Future Oncol. 2017, 13, 249-261. [CrossRef] [PubMed]

45. Yuan, J.; Kensler, K.H.; Hu, Z.; Zhang, Y.; Zhang, T.; Jiang, J.; Xu, M.; Pan, Y.; Long, M.; Montone, K.T.; et al. Integrative comparison of the genomic and transcriptomic landscape between prostate cancer patients of predominantly African or European genetic ancestry. PLoS Genet. 2020, 16, e1008641. [CrossRef] [PubMed]

46. Hubbard, G.K.; Mutton, L.N.; Khalili, M.; McMullin, R.P.; Hicks, J.L.; Bianchi-Frias, D.; Horn, L.A.; Kulac, I.; Moubarek, M.S.; Nelson, P.S.; et al. Combined MYC Activation and Pten Loss Are Sufficient to Create Genomic Instability and Lethal Metastatic Prostate Cancer. Cancer Res. 2016, 76, 283-292. [CrossRef]

47. Liu, W.; Xie, C.C.; Thomas, C.Y.; Kim, S.-T.; Lindberg, J.; Egevad, L.; Wang, Z.; Zhang, Z.; Sun, J.; Sun, J.; et al. Genetic markers associated with early cancer-specific mortality following prostatectomy. Cancer 2013, 119, 2405-2412. [CrossRef]

48. Bassi, C.; Ho, J.; Srikumar, T.; Dowling, R.J.O.; Gorrini, C.; Miller, S.J.; Mak, T.W.; Neel, B.G.; Raught, B.; Stambolic, V. Nuclear PTEN controls DNA repair and sensitivity to genotoxic stress. Science 2013, 341, 395-399. [CrossRef]

49. Barbieri, C.E.; Baca, S.C.; Lawrence, M.S.; Demichelis, F.; Blattner, M.; Theurillat, J.-P.; White, T.A.; Stojanov, P.; Van Allen, E.; Stransky, N.; et al. Exome sequencing identifies recurrent SPOP, FOXA1 and MED12 mutations in prostate cancer. Nat. Genet. 2012, 44, 685-689. [CrossRef]

50. An, J.; Wang, C.; Deng, Y.; Yu, L.; Huang, H. Destruction of full-length androgen receptor by wild-type SPOP, but not prostate-cancer-associated mutants. Cell Rep. 2014, 6, 657-669. [CrossRef]

51. Mani, R.-S. The emerging role of speckle-type POZ protein (SPOP) in cancer development. Drug Discov. Today 2014, 19, 1498-1502. [CrossRef]

52. Tonon, L.; Fromont, G.; Boyault, S.; Thomas, E.; Ferrari, A.; Sertier, A.-S.; Kielbassa, J.; Le Texier, V.; Kamoun, A.; Elarouci, N.; et al. Mutational Profile of Aggressive, Localised Prostate Cancer from African Caribbean Men Versus European Ancestry Men. Eur. Urol. 2019, 75, 11-15. [CrossRef]

53. Blattner, M.; Lee, D.J.; O’Reilly, C.; Park, K.; MacDonald, T.Y.; Khani, F.; Turner, K.R.; Chiu, Y.-L.; Wild, P.J.; Dolgalev, I.; et al. SPOP mutations in prostate cancer across demographically diverse patient cohorts. Neoplasia 2014, 16, 14-20. [CrossRef] [PubMed] 
54. Wu, Y.-M.; Cieślik, M.; Lonigro, R.J.; Vats, P.; Reimers, M.A.; Cao, X.; Ning, Y.; Wang, L.; Kunju, L.P.; de Sarkar, N.; et al. Inactivation of CDK12 Delineates a Distinct Immunogenic Class of Advanced Prostate Cancer. Cell 2018, 173, 1770-1782.e14. [CrossRef] [PubMed]

55. Scher, H.I.; Fizazi, K.; Saad, F.; Taplin, M.-E.; Sternberg, C.N.; Miller, K.; de Wit, R.; Mulders, P.; Chi, K.N.; Shore, N.D.; et al. Increased survival with enzalutamide in prostate cancer after chemotherapy. N. Engl. J. Med. 2012, 367, 1187-1197. [CrossRef] [PubMed]

56. Chen, Y.; Clegg, N.J.; Scher, H.I. Anti-androgens and androgen-depleting therapies in prostate cancer: New agents for an established target. Lancet Oncol. 2009, 10, 981-991. [CrossRef]

57. Mizokami, A.; Koh, E.; Fujita, H.; Maeda, Y.; Egawa, M.; Koshida, K.; Honma, S.; Keller, E.T.; Namiki, M. The adrenal androgen androstenediol is present in prostate cancer tissue after androgen deprivation therapy and activates mutated androgen receptor. Cancer Res. 2004, 64, 765-771. [CrossRef]

58. Watson, P.A.; Chen, Y.F.; Balbas, M.D.; Wongvipat, J.; Socci, N.D.; Viale, A.; Kim, K.; Sawyers, C.L. Constitutively active androgen receptor splice variants expressed in castration-resistant prostate cancer require full-length androgen receptor. Proc. Natl. Acad. Sci. USA 2010, 107, 16759-16765. [CrossRef]

59. Hernández-Llodrà, S.; Segalés, L.; Safont, A.; Juanpere, N.; Lorenzo, M.; Fumadó, L.; Rodríguez-Vida, A.; Cecchini, L.; Bellmunt, J.; Lloreta-Trull, J. SPOP and FOXA1 mutations are associated with PSA recurrence in ERG wt tumors, and SPOP downregulation with ERG-rearranged prostate cancer. Prostate 2019, 79, 1156-1165. [CrossRef]

60. Heemers, H.V.; Tindall, D.J. Androgen receptor (AR) coregulators: A diversity of functions converging on and regulating the AR transcriptional complex. Endocr. Rev. 2007, 28, 778-808. [CrossRef]

61. Azad, A.A.; Volik, S.V.; Wyatt, A.W.; Haegert, A.; Le Bihan, S.; Bell, R.H.; Anderson, S.A.; McConeghy, B.; Shukin, R.; Bazov, J.; et al. Androgen Receptor Gene Aberrations in Circulating Cell-Free DNA: Biomarkers of Therapeutic Resistance in Castration-Resistant Prostate Cancer. Clin. Cancer Res. 2015, 21, 2315-2324. [CrossRef] [PubMed]

62. LaTulippe, E.; Satagopan, J.; Smith, A.; Scher, H.; Scardino, P.; Reuter, V.; Gerald, W.L. Comprehensive gene expression analysis of prostate cancer reveals distinct transcriptional programs associated with metastatic disease. Cancer Res. 2002, 62, 4499-4506. [PubMed]

63. Chang, K.-H.; Li, R.; Kuri, B.; Lotan, Y.; Roehrborn, C.G.; Liu, J.; Vessella, R.; Nelson, P.S.; Kapur, P.; Guo, X.; et al. A gain-of-function mutation in DHT synthesis in castration-resistant prostate cancer. Cell 2013, 154, 1074-1084. [CrossRef] [PubMed]

64. Lu, C.; Luo, J. Decoding the androgen receptor splice variants. Transl. Androl. Urol. 2013, 2, 178-186.

65. Lu, C.; Brown, L.C.; Antonarakis, E.S.; Armstrong, A.J.; Luo, J. Androgen receptor variant-driven prostate cancer II: Advances in laboratory investigations. Prostate Cancer Prostatic Dis. 2020, 23, 381-397. [CrossRef]

66. Bastos, D.A.; Antonarakis, E.S. CTC-derived AR-V7 detection as a prognostic and predictive biomarker in advanced prostate cancer. Expert Rev. Mol. Diagn. 2018, 18, 155-163. [CrossRef]

67. Graf, R.P.; Hullings, M.; Barnett, E.S.; Carbone, E.; Dittamore, R.; Scher, H.I. Clinical Utility of the Nuclear-localized AR-V7 Biomarker in Circulating Tumor Cells in Improving Physician Treatment Choice in Castration-resistant Prostate Cancer. Eur. Urol. 2020, 77, 170-177. [CrossRef]

Publisher's Note: MDPI stays neutral with regard to jurisdictional claims in published maps and institutional affiliations.

(C) 2020 by the authors. Licensee MDPI, Basel, Switzerland. This article is an open access article distributed under the terms and conditions of the Creative Commons Attribution (CC BY) license (http://creativecommons.org/licenses/by/4.0/). 